UDC 332.1(470+571)

Submitted: 02.09.2020

LBC 65.04

Accepted: 24.09 .2020

\title{
MACRO-REGIONS IN THE SPATIAL DEVELOPMENT STRATEGY OF RUSSIA: VERIFICATION OF BORDERS BY PROMISING ECONOMIC SPECIALIZATIONS ${ }^{1}$
}

\author{
Viktor I. Blanutsa \\ V.B. Sochava Institute of Geography of Siberian Branch of the Russian Academy of Sciences, \\ Irkutsk, Russian Federation
}

\begin{abstract}
The purpose of the study is to verify the correspondence between the inclusion of regions in macroregions and the distribution of promising economic specializations by regions. The initial data are taken from the "Spatial Development Strategy of the Russian Federation for the Period until 2025". The theoretical basis of the study was the concept of "economic convergence." According to the initial hypothesis, the boundaries of macro-regions reflect the distribution of promising specializations by regions in the case of relative convergence of Russian regions into twelve clubs (macro-regions). To test the hypothesis, the idea of contrasting and blurry (fuzzy) boundaries of regions is formulated. A quantitative measure of the difference between the two regions by a combination of promising economic specializations is proposed. To confirm the club convergence hypothesis, it is necessary that the interregional boundaries along the perimeter of macro-regions be contrasted, and within the macro-regions - blurred. Calculations showed that most of the inter-regional borders are blurred, and contrasting borders are more common within macroregions than along their perimeter. Therefore, the initial hypothesis was recognized as erroneous and an alternative hypothesis was adopted when the union of regions into groups according to a combination of promising economic specializations does not correspond to the union of regions into macro-regions. The results can be used to adjust the spatial development strategy. It is proposed to take into account Russias transition to the digital economy and the introduction of artificial intelligence systems in determining promising specializations.

Key words: spatial development strategy, promising economic specialization, macro-region, economic convergence, measure of difference, contrasting border, region, Russian Federation.

Citation. Blanutsa V.I. Macro-Regions in the Spatial Development Strategy of Russia: Verification of Borders by Promising Economic Specializations. Journal of Volgograd State University. Economics, 2020, vol. 22, no. 3, pp. 30-41. (in Russian). DOI: https://doi.org/10.15688/ek.jvolsu.2020.3.3

УДК $332.1(470+571)$

Дата поступления статьи: 02.09.2020

ББК 65.04

Дата принятия статьи: 24.09.2020

\section{МАКРОРЕГИОНЫ В СТРАТЕГИИ ПРОСТРАНСТВЕННОГО РАЗВИТИЯ РОССИИ: ВЕРИФИКАЦИЯ ГРАНИЦ ПО ПЕРСПЕКТИВНЫМ ЭКОНОМИЧЕСКИМ СПЕЦИАЛИЗАЦИЯМ ${ }^{1}$}

\author{
Виктор Иванович Блануца \\ Институт географии им. В.Б. Сочавы СО РАН, г. Иркутск, Российская Федерация
}

Аннотация. Цель исследования связана с проверкой соответствия между включением регионов в макрорегионы и распределением перспективных экономических специализаций по регионам. Исходные дан- 
ные взяты из Стратегии пространственного развития Российской Федерации на период до 2025 года. Теоретической основой исследования стала концепция «экономической конвергенции». Согласно исходной гипотезе, границы макрорегионов отражают распределение перспективных специализаций по регионам в случае относительной конвергенции российских регионов в 12 клубов (макрорегионов). Для проверки гипотезы сформулировано представление о контрастных и размытых (нечетких) границах регионов. Предложена количественная мера различия между двумя регионами по сочетанию перспективных экономических специализаций. Для подтверждения гипотезы клубной конвергенции необходимо, чтобы межрегиональные границы по периметру макрорегионов были контрастными, а внутри макрорегионов - размытыми. Расчеты показали, что большинство межрегиональных границ являются размытыми, а контрастные границы чаще встречаются внутри макрорегионов, чем по их периметру. Поэтому исходная гипотеза признана ошибочной и принята альтернативная гипотеза, когда объединение регионов в группы по сочетанию перспективных экономических специализаций не соответствует объединению регионов в макрорегионы. Полученные результаты могут использоваться для корректировки стратегии пространственного развития.

Ключевые слова: стратегия пространственного развития, перспективная экономическая специализация, макрорегион, экономическая конвергенция, мера различия, контрастная граница, регион.

Цитирование. Блануца В. И. Макрорегионы в стратегии пространственного развития России: верификация границ по перспективным экономическим специализациям // Вестник Волгоградского государственного университета. Экономика. - 2020. - Т. 22, № 3. -C. 30-41. - DOI: https://doi.org/10.15688/ek.jvolsu.2020.3.3

\section{Введение}

После примерно пяти лет обсуждений и согласований в феврале 2019 г. утверждена Стратегия пространственного развития Российской Федерации на период до 2025 года (далее - Стратегия) [Распоряжение Правительства РФ от 13.02.2019 ...]. В ней представлено несколько нововведений (институций), среди которых отметим перспективные экономические специализации субъектов Российской Федерации (перечислены в Приложении 1 для каждого региона, кроме Москвы) и макрорегионы (Приложение 2). Стратегия подверглась критике в отечественном научном сообществе [Бухвальд и др., 2019; Иванов и др., 2019; Котов, 2019; Лексин, 2019; Минакир, 2019; и др.]. Однако в публикациях не предпринимались попытки количественно оценить непротиворечивость Стратегии в плане соответствия одних новаций другим. Поэтому целью нашего исследования стала проверка (верификация) обоснованности выделения (делимитации) макрорегионов России по распределению перспективных экономических специализаций между регионами. В мировой науке такая цель еще не ставилась, хотя неоднократно подчеркивалась связь между экономической специализацией региона и его отнесением к той или иной группе регионов в стратегическом планировании [Brenner et al., 2016; Capello et al., 2019; Chapman et al., 2017; Smart Specialization Policy ..., 2019]. Практическая значимость исследования связана с необходимостью корректировки Стратегии, поскольку ее неточности и противоречия приведут к ошибкам при разработке стратегий социально-экономического развития отдельных регионов и их групп (макрорегионов).

Проблематика выделения макрорегионов как некоторого промежуточного звена между государством в целом и его регионами не нова для России [Бухвальд и др., 2019; Митрофанова, 2008; Рой, 2012; Чертков, 2011], но только в Стратегии был официально закреплен статус такого территориального образования, как макрорегион. В последние годы до Стратегии макрорегионом называли федеральный округ. Теперь 4 округа (Южный, Северо-Кавказский, Уральский и Дальневосточный) стали макрорегионами, а каждый из 4 оставшихся округов разделен на 2 макрорегиона (Центральный округ - на Центральный и Центрально-Черноземный макрорегионы, Северо-Западный - на Северо-Западный и Северный, Приволжский - на Волго-Камский и Волго-Уральский, Сибирский - на Южно-Сибирский и Ангаро-Енисейский). Если судить по динамике публикационной активности в отечественных научных журналах (см. рис. 1), то в последнее время наблюдается рост интереса к исследованию макрорегионов (409 статей в 2015-2019 гг. из 669 статей в 20012019 гг.). При этом по ключевому слову «макрорегион стратегии пространственного развития» в «Научной электронной библиотеке» 


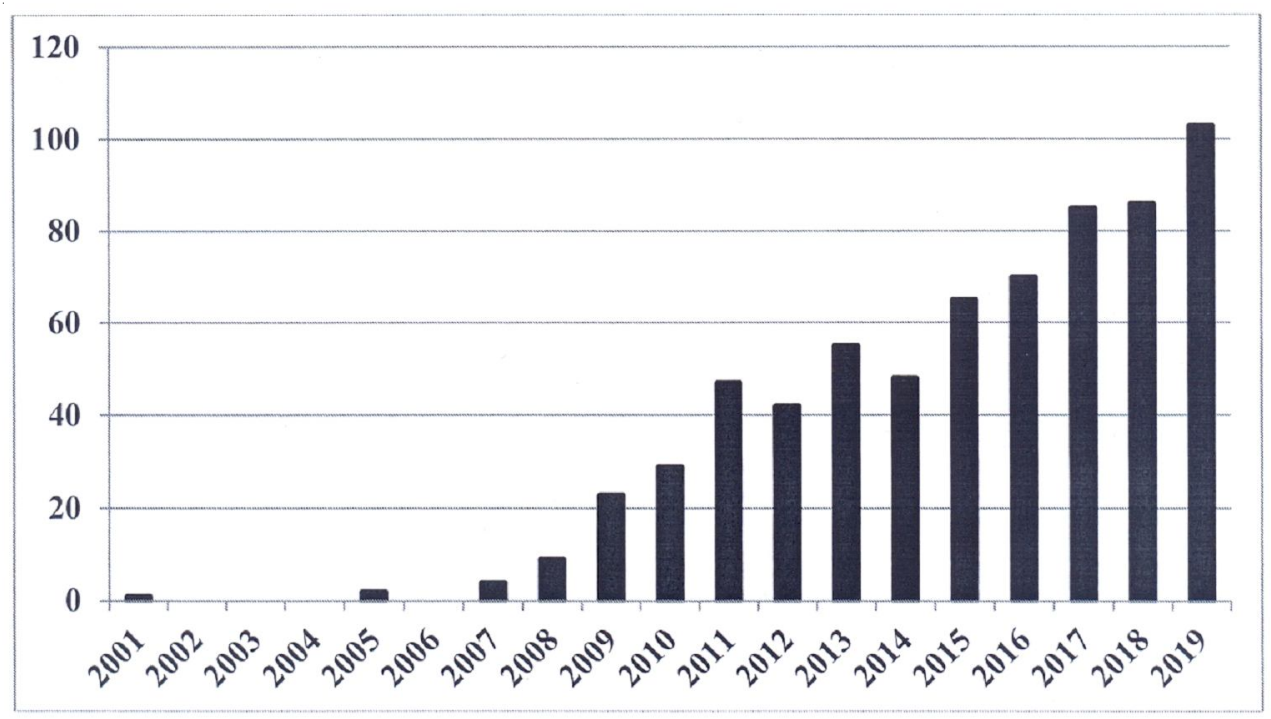

Рис. 1. Изменение ежегодного количества отечественных журнальных статей, посвященных изучению макрорегионов

Примечание. Составлено автором по результатам анализа статей в «Научной электронной библиотеке» (www.elibrary.ru) на 10 мая 2020 года.

(www.elibrary.ru; на 10.05.2020) было обнаружено всего 6 статей. Из них только в 1 работе [Наумов и др., 2019] проанализировано распределение минерально-сырьевой специализации по регионам и макрорегионам России. Вне 6 статей оказалась еще 1 публикация [Преображенский, 2019], в которой в рамках Урало-Поволжья ставились под сомнение несколько участков границ макрорегионов. Однако ни в одной из 669 статей не анализировались все границы макрорегионов по всем перспективным экономическим специализациям.

В Стратегии на основе общероссийского классификатора видов экономической деятельности выделены 34 агрегированные специализации. Среди них наиболее часто встречаются: «производство прочих готовых изделий» (в 83 регионах), «туризм» (72), «растениеводство и животноводство» (70), «производство машин и оборудования, не включенных в другие группировки» (68), «производство пищевых продуктов» (68), «производство химических веществ и химических продуктов» (67) и «производство электрического оборудования» (66). Наименее представлены: «обеспечение электрической энергией, газом и паром» (только в Амурской области), «ремонт и монтаж машин и оборудования (ремонт и техническое обслуживание судов и лодок)» (только в Республике Саха (Якутия) и Сахалинской области) и «производство табачных изделий» (в 5 регионах). Среди регионов наибольшее количество перспективных специализаций намечено в Республике Татарстан (27), Нижегородской (27) и Ростовской (27) областях, Ставропольском крае (26), Волгоградской (25) и Ленинградской (25) областях, а меньше всего - в Ненецком автономном округе (4), республиках Алтай (5) и Тыва (5), Магаданской области (5), Республике Калмыкия (6), Чукотском (6) и Ямало-Ненецком (6) автономных округах.

Если опираться на текст Стратегии, то основными принципами выделения макрорегионов являются «соседское положение субъектов Российской Федерации, схожие природно-климатические и социально-экономические условия для жизни и экономической деятельности, наличие в пределах макрорегиона устойчивых пассажирских перевозок... наличие (или необходимость создания) крупных межрегиональных объектов отраслей социальной сферы федерального значения... значительный потенциал межрегионального сотрудничества в рамках реализации перспективных экономических специализаций субъектов Российской Федерации и достраивания цепочек добавленной стоимости в пределах макрорегионов, в том числе для реализации крупных межрегиональных инвестиционных 
проектов, наличие (необходимость создания) объектов транспортной, энергетической, информационно-телекоммуникационной инфраструктуры, обеспечивающих усиление экономической связности субъектов... а также выход к международным рынкам и (или) транспортным коридорам "Запад - Восток" и "Север - Юг”, и в пределах которых может осуществляться координация социально-экономического развития... субъектов» [Распоряжение Правительства РФ от 13.02.2019 ...]. Из этого нечеткого набора принципов делимитации макрорегионов выделим «потенциал межрегионального сотрудничества в рамках реализации перспективных экономических специализаций», поскольку в Стратегии представлены как перспективные специализации каждого региона, так и объединение регионов в макрорегионы. При выделении регионов и других целостных территориальных образований обычно минимизируются различия внутри образования и достигают максимума между образованиями [Блануца, 2018a; Duque et al., 2007; Karlsson et al., 2006]. Отсюда можно конкретизировать цель исследования - проверить значимость различий по сочетанию перспективных экономических специализаций на границах между макрорегионами при отсутствии такой значимости на границах регионов внутри макрорегионов.

\section{Гипотезы и методы исследования}

Верификация границ может опираться на концепцию «экономической конвергенции» [Barro, 1991; Barro et al., 1992; Islam, 2003; Sala-iMartin, 1996], согласно которой траектории социально-экономического развития регионов сходятся к одному уровню. Если это так, то имеет место абсолютная (общая) конвергенция, а если траектории сходятся к нескольким иерархическим уровням, то наблюдается относительная (клубная) конвергенция [Barrios et al., 2019; Bartkowska et al., 2012; Galor, 1996; Marelli et al., 2019]. При этом уровень фиксируется не одним значением, а некоторым интервалом. Например, в Европейском союзе конвергенция регионов может быть достигнута при наличии не менее $75 \%$ от среднего валового регионального продукта на душу населения в каждом регионе [Воронов, 2014].
Обычно расчеты ведутся по производительности труда или душевому ВВП [Kinfemichael et al., 2019; Napolitano et al., 2018], но не исключен учет различных моделей и структур [Monfort et al., 2018]. В нашем исследовании по Стратегии исходной гипотезой является относительная конвергенция всех российских регионов в 12 клубов (макрорегионов). В таком случае альтернативной гипотезой будет абсолютная конвергенция регионов или распределение регионов по клубам, территориально не совпадающим с макрорегионами.

Для проверки гипотезы целесообразно оперировать двумя видами границ - контрастными (между регионами со значительным различием по сочетанию перспективных экономических специализаций) и размытыми (нечеткими). Ко второму виду относятся все границы с незначительными различиями между соседними регионами. Тогда гипотеза клубной конвергенции подтверждается при наличии контрастных границ между макрорегионами и размытых границ внутри каждого макрорегиона, а отклоняется во всех остальных случаях. Для количественной оценки степени контрастности границ предлагается следующая формула:

$$
D_{i j}=1-\frac{2 K_{i j}}{K_{i}+K_{j}}
$$

где $D_{i j}$ - мера различия между регионами $i$ и $j$ по сочетанию перспективных экономических специализаций; $K_{i j}$ - количество одноименных специализаций, встречающихся в обоих регионах; $K_{i}$ - количество всех специализаций в $i$-м регионе; $K_{j}$ - количество всех специализаций в $j$-м регионе.

Наибольшая контрастность достигается на границе, разделяющей регионы с совершенно разными специализациями $\left(D_{i j}=1\right)$, а наименьшая - между регионами с одинаковым набором специализаций $\left(D_{i j}=0\right)$. Вопрос о критерии значимости различий между сочетаниями специализаций в регионах довольно сложный, требующий специального исследования. Поэтому в рамках первого исследования по рассматриваемой проблематике будем исходить из максимально допустимого расхождения между социально-экономическими структурами, которое не может превышать $50 \%$ от максимального сходства для исключения 
возможности формирования структур с другим доминирующим сочетанием [Блануца, 2018а; Блануца, 2018б]. Отсюда контрастными будут считаться все межрегиональные границы с $D_{i j} \geq 0,51$, а размытыми границами c $D_{i j} \leq 0,50$.

\section{Результаты и обсуждение}

Значения мер различия между всеми регионами были сведены в симметричную матрицу $\left\{D_{i j}\right\}$, имеющую размер $84 \times 84$. Перемножение этой матрицы на матрицу смежности (соседства) российских регионов (если есть общая граница, то 1, в противном случае - 0) позволило получить массив данных, необходимый для верификации границ. При этом в расчетах было принято, что Калининградская область связана с Ленинградской областью (через Балтийское море), Республика Крым - с Краснодарским краем (через мост), а Сахалинская область - с Хабаровским краем (через паром). Среди всех регионов наибольшее различие зафиксировано между Чувашской Республикой и Магаданской областью $\left(D_{i j}=0,92\right)$, Республикой Саха (Якутия) и Псковской областью $(0,92)$, Магаданской и Ульяновской областями $(0,92)$, а наименьшее различие - между Республикой Татарстан и Нижегородской областью $(0,04)$. По межрегиональным границам наибольший контраст имел место между Республикой Алтай и Ал- тайским краем $(0,72)$, а наименьший - между Калужской и Орловской $(0,06)$, Курской и Орловской $(0,06)$ областями.

Внешние границы 12 макрорегионов проходили по 68 межрегиональным границам, из которых только 4 были контрастными (между Республикой Коми и Кировской областью, республиками Дагестан и Калмыкия, Ставропольским краем и Республикой Калмыкия, Красноярским краем и Ямало-Ненецким автономным округом). Внутри всех макрорегионов была 121 межрегиональная граница, среди них 15 относились к контрастным рубежам. Из этого следует, что гипотеза клубной конвергенции в 12 макрорегионов отклоняется как ошибочная, поскольку нет 68 контрастных межрегиональных границ по периметру макрорегионов и 121 размытой границы внутри макрорегионов. Распределение контрастных и размытых межрегиональных границ по внешним и внутренним границам макрорегионов (табл. 1) показывает, что 6 макрорегионов по внешнему периметру не имеют ни одной контрастной межрегиональной границы. Из этого следует, что по сочетанию перспективных экономических специализаций половина макрорегионов не имеют никаких оснований для выделения. В оставшихся макрорегионах удельный вес контрастных внешних границ не достигает даже $50 \%$, что также не дает основания для их выделения. Кроме этого, внутри шести макрорегионов встречаются контра-

Таблича 1

Количество контрастных и размытых межрегиональных границ по внешнему периметру и внутри макрорегионов Российской Федерации

\begin{tabular}{|l|c|c|c|c|}
\hline \multirow{2}{*}{ Макрорегион } & \multicolumn{2}{|c|}{ Внешние границы } & \multicolumn{2}{c|}{ Внугренние границы } \\
\cline { 2 - 5 } & Контрастные & Размытые & Контрастные & Размытые \\
\hline Центральный & 0 & 19 & 1 & 22 \\
\hline Центрально-Черноземный & 0 & 11 & 0 & 7 \\
\hline Северо-Западный & 0 & 9 & 0 & 10 \\
\hline Северный & 1 & 8 & 2 & 1 \\
\hline Южный & 2 & 6 & 3 & 6 \\
\hline Северо-Кавказский & 2 & 3 & 0 & 11 \\
\hline Волго-Камский & 1 & 19 & 0 & 14 \\
\hline Волго-Уральский & 0 & 17 & 0 & 7 \\
\hline Уральско-Сибирский & 1 & 12 & 0 & 8 \\
\hline Южно-Сибирский & 0 & 8 & 2 & 7 \\
\hline Ангаро-Енисейский & 1 & 11 & 2 & 3 \\
\hline Дальневосточный & 0 & 5 & 5 & 10 \\
\hline
\end{tabular}

Примечание. Составлено автором. Межрегиональные границы между двумя макрорегионами учитываются в обоих макрорегионах. Размытые границы имеют $D_{i j} \leq 0,50$, а контрастные границы $-D_{i j} \geq 0,51$. 
стные границы, что не должно быть при правильной делимитации клубов конвергенции.

Размещение контрастных межрегиональных границ по территории России (рис. 2) указывает на существование одного большого «макрорегиона», по периферии которого находится несколько проблемных регионов. Среди таких регионов выделяется Республика Калмыкия - единственный субъект Российской Федерации, имеющий контрастные границы со всеми соседями. Ненецкий автономный округ существенно отличается от Архангельской области, с которой планируется объединение, и Республики Коми, но имеет размытую границу с Ямало-Ненецким автономным округом. Отсюда вопрос правительству: достаточно ли сходства перспективных экономических специализаций для объединения Ненецкого и Ямало-Ненецкого автономных округов? Республики Алтай и Тыва имеют по две контрастные границы с экономически развитыми соседями, а Республика Саха (Якутия) тяготеет к Красноярскому краю и Иркутской области при создании существенной дистанции (по перспективным специализациям) от 4 (из 5) соседей по Дальневосточ- ному федеральному округу. По одной контрастной границе имеют Костромская область и Еврейская автономная область.

Вывод о невозможности объединения российских регионов в 12 макрорегионов по сочетанию перспективных экономических специализаций опирался на анализ контрастности границ. Однако теоретически не исключена ситуация, при которой граница между макрорегионами А и Б может быть размытой при существенных различиях $\left(D_{i j} \geq 0,51\right)$ между группами регионов А и Б. Такое происходит при сходстве приграничных регионов и значительном различии между внутренними регионами А и внутренними регионами Б. В данной ситуации целесообразно оперировать значениями наведенной контрастности границ, когда рассчитывается средняя мера различия между регионами, входящими в 2 соседних макрорегиона, а полученная величина приписывается границе между этими макрорегионами. Для сравнения были также рассчитаны средние значения меры различия между регионами в каждом макрорегионе. Полученные величины (см. табл. 2) подтверждают общий вывод при двух исключениях - границы меж-

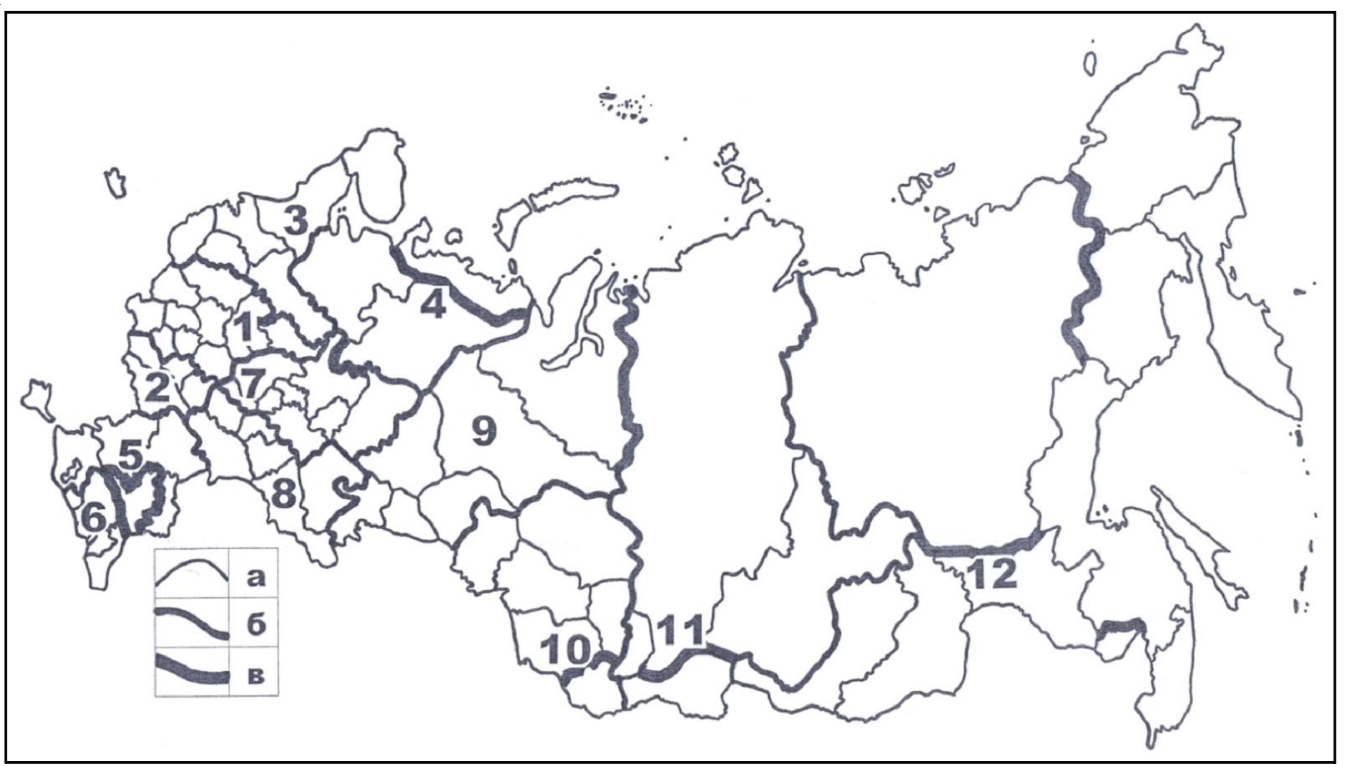

Рис. 2. Макрорегионы Российской Федерации с выделением контрастных границ по сочетанию перспективных экономических специализаций:

границы: $a$ - регионов, $\sigma$ - макрорегионов, 6 - контрастных территорий; макрорегионы: 1 - Центральный, 2 - Центрально-Черноземный, 3 - Северо-Западный, 4 - Северный, 5 - Южный, 6 - Северо-Кавказский, 7 - Волго-Камский, 8 - Волго-Уральский, 9 - Уральско-Сибирский, 10 - Южно-Сибирский, 11 - Ангаро-Енисейский, 12 - Дальневосточный

Примечание. Составлено автором по: [Распоряжение Правительства РФ от 13.02.2019 ...] и таблице 1. 
Средняя мера различия между регионами одного (по главной диагонали) и двух соседних (вне главной диагонали) макрорегионов России

\begin{tabular}{|c|c|c|c|c|c|c|c|c|c|c|c|c|}
\hline Макрорегионы & 1 & 2 & 3 & 4 & 5 & 6 & 7 & 8 & 9 & 10 & 11 & 12 \\
\hline 1 & $\mathbf{0 , 2 3}$ & 0,20 & 0,38 & - & - & - & 0,23 & 0,24 & - & - & - & - \\
\hline 2 & 0,20 & $\mathbf{0 , 1 9}$ & - & - & 0,29 & - & - & 0,23 & - & - & - & - \\
\hline 3 & 0,38 & - & $\mathbf{0 , 4 5}$ & 0,55 & - & - & 0,36 & - & - & - & - & - \\
\hline 4 & - & - & 0,55 & $\mathbf{0 , 5 3}$ & - & - & 0,60 & - & 0,49 & - & - & - \\
\hline 5 & - & 0,29 & - & - & $\mathbf{0 , 3 3}$ & 0,32 & - & 0,28 & - & - & - & - \\
\hline 6 & - & - & - & - & 0,32 & $\mathbf{0 , 2 8}$ & - & - & - & - & - & - \\
\hline 7 & 0,23 & - & 0,36 & 0,60 & - & - & $\mathbf{0 , 2 3}$ & 0,23 & 0,36 & - & - & - \\
\hline 8 & 0,24 & 0,23 & - & - & 0,28 & - & 0,23 & $\mathbf{0 , 1 9}$ & 0,33 & - & - & - \\
\hline 9 & - & - & - & 0,49 & - & - & 0,36 & 0,33 & $\mathbf{0 , 4 1}$ & 0,38 & 0,42 & - \\
\hline 10 & - & - & - & - & - & - & - & - & 0,38 & $\mathbf{0 , 3 9}$ & 0,39 & - \\
\hline 11 & - & - & - & - & - & - & - & - & 0,42 & 0,39 & $\mathbf{0 , 4 2}$ & 0,49 \\
\hline 12 & - & - & - & - & - & - & - & - & - & - & 0,49 & $\mathbf{0 , 5 0}$ \\
\hline
\end{tabular}

Примечание. Составлено автором. Номера макрорегионов приведены по рисунку 2. Значения на главной диагонали выделены полужирным шрифтом. Знак «-» указывает на отсутствие общей границы между двумя макрорегионами.

ду Северным и Северо-Западным, Северным и Волго-Камским макрорегионами являются контрастными. Однако эти различия нивелируются контрастными границами внутри Северного макрорегиона. Причина такой ситуации связана с Ненецким автономным округом, перспективные специализации которого существенно отличаются от специализаций регионов в 3 отмеченных макрорегионах. Кроме этого, в Южном, Южно-Сибирском и Дальневосточном макрорегионах наблюдается «инверсия» - различия внутри макрорегиона не меньше, чем различия с соседними макрорегионами, что лишний раз указывает на произвольность границ макрорегионов с позиции перспективных экономических специализаций.

В исследовании анализировались только перспективные экономические специализации, приведенные в Стратегии. Однако эти специализации и их распределение по регионам вызывают ряд вопросов. Можно ли считать специализацией то, что перспективно для каждого региона? Например, «производство прочих готовых изделий» прописано для всех регионов, кроме Псковской области. Это ошибка или Псковская область не готова к такой всеохватывающей специализации? Не все понятно с уникальными специализациями. Если в любой точке России потребуется судоремонт, то транспортные средства придется доставлять исключительно в Республику Саха (Якутия) и Сахалинскую область (только здесь «ремонт и техническое обслуживание судов и лодок»)? А как быть с экспортом электроэнергии из тех регионов, где наблюдается ее избыток, если «обеспечение электрической энергией, газом и паром» перспективно только для Амурской области? Почему в специализации на «туризме» отказано ряду регионов с уникальными природными и этнографическими комплексами (среди них Республика Тыва, Забайкальский край, Ненецкий и Чукотский автономные округа)? Если в регионе имеется много рек и озер, то почему не перспективно «рыболовство и рыбоводство» (к примеру, в республиках Бурятия и Татарстан, Красноярском и Пермском крае, Амурской, Волгоградской, Иркутской, Новосибирской, Самарской и Саратовской областях)? Возникают различные вопросы и при сравнении специализаций. Обратимся только к цепочке «лесоводство и лесозаготовки» $\rightarrow$ «обработка древесины и производство изделий из дерева, кроме мебели» $\rightarrow$ «производство мебели». При такой структуризации полный цикл перспективен для 9 из 27 регионов лесозаготовки. Тогда почему для Камчатского края, республик Алтай и Тыва не перспективна хотя бы «обработка древесины», а для 15 регионов «производство мебели»? При этом в Стратегии перечисляются именно перспективные, а не существующие экономические специализации. Получается, что федеральный центр лишает некоторые регионы даже надежды на 
будущую диверсификацию экономической деятельности.

Ничего не сказано в Стратегии о переходе регионов к цифровой экономике и возникающих при этом специализациях. С большой долей условности о таком переходе можно судить по специализации на «производстве компьютеров, электронных и оптических изделий» и «деятельности в области информации и связи». Обе специализации перспективны для 46 регионов. Значит ли это, что в оставшихся регионах не будет развиваться цифровая экономика? Может ли территориальная структура цифровой экономики быть выражена через 12 макрорегионов? Здесь необходимы специальные исследования, но по первым результатам, указывающим на 45 цифровых регионов России [Блануца, 2018а; Блануца, 2018б], можно предположить об иной структуре, не укладывающейся в макрорегионы и федеральные округа. Кроме этого, рассматриваемые специализации находятся бесконечно далеко от искусственного интеллекта, развитие которого запланировано по другому стратегическому документу Российской Федерации. Как могут называться перспективными специализации, не учитывающие будущую цифровую экономику и распределение производственных, транспортных и сервисных систем искусственного интеллекта по регионам?

\section{Заключение}

Гипотеза конвергенции российских регионов в 12 клубов (макрорегионов) по сочетанию перспективных экономических специализаций не подтвердилась. Поэтому была принята альтернативная гипотеза, которая априори связывалась с абсолютной экономической конвергенцией или относительной конвергенцией в иные клубы. Абсолютная конвергенция была исключена по причине наличия нескольких контрастных границ между регионами. Из этого следует, что границы макрорегионов, приведенные в Стратегии, не отражают распределение регионов по группам со специфическими сочетаниями перспективных специализаций. Каков состав этих групп (клубов) - предмет дальнейших исследований. В целом по Стратегии можно констатировать, что «значительный потенциал межрегионального сотрудничества в рамках реализации перспективных экономических специализаций в пределах макрорегионов» не может быть воплощен в жизнь по причине размытых границ между макрорегионами и контрастных границ внутри макрорегионов. Поэтому «потенциал сотрудничества» может быть реализован в любых группах регионов (за исключением разделенных контрастными границами), не привязанных к макрорегионам.

Полученные результаты указывают на наличие ошибок в Стратегии. Они были обнаружены при сопоставлении макрорегионов с распределением перспективных экономических специализаций по регионам. В дальнейшем необходимо провести проверку Стратегии по сопоставлениям: перспективных экономических специализаций с перспективными центрами экономического роста и геостратегическими территориями, перспективных центров роста с макрорегионами и геостратегическими территориями, макрорегионов с геостратегическими территориями. Это позволит осуществить независимую экспертизу Стратегии и внести в нее необходимые корректировки. Особо следует разобраться с перспективными специализациями, отсутствующими в Стратегии, но необходимыми для развития отдельных регионов и всей страны. При этом можно опираться на концепцию «умной специализации» [Borsekova et al., 2017; Foray, 2018; Ranga, 2018; Smart Specialization Policy ..., 2019], позволяющую выявлять эндогенные факторы экономического роста и усиления конкурентоспособности регионов.

Перспективы дальнейших исследований по проблематике макрорегионов могут быть связаны со следующими направлениями: проведением интегрального экономического районирования территории Российской Федерации, выявлением зон экономического влияния крупнейших российских городов, делимитацией территориальных цифровых платформ для развития платформенной экономики [Блануца, 2019], определением макрорегиональной структуры пространственной диффузии экономических инноваций и идентификацией межрегиональных кластеров взаимодействия автономных систем искусственного интеллекта. 


\section{ПРИМЕЧАНИЕ}

${ }^{1}$ Публикация подготовлена в рамках реализации государственного задания Института географии им. В.Б. Сочавы СО РАНна 2020 г., № государственной регистрации проекта АААА-A17-117041910166-3.

The reported publication was carried out in the framework of implementing the State Task of the V.B. Sochava Institute of Geography of Siberian Branch of the Russian Academy of Sciences for 2020, project state registration no. AAAA-A17-117041910166-3.

\section{СПИСОК ЛИТЕРАТУРЫ}

Блануца, В. И. Социально-экономическое районирование в эпоху больших данных / В. И. Блануца. - М. : ИНФРА-М, 2018а. - 194 с.

Блануца, В. И. Территориальная структура цифровой экономики России: предварительная делимитация «умных» городских агломераций и регионов / В. И. Блануца // Пространственная экономика. - 2018б. - № 2. - С. 17-35. DOI: https://doi.org/10.14530/se.2018.2.017-035.

Блануца, В. И. Цифровая экономика Сибири: территориальные платформы для кластеров / В. И. Блануца // Актуальные проблемы экономики и права. - 2019. - Т. 13, № 3. - С. 1362-1374. - DOI: https://doi.org/10.21202/1993-047X.13.2019.3.

Бухвальд, Е. М. Макрорегионы как новация стратегирования пространственного развития экономики России / Е. М. Бухвальд, О. Н. Валентик // Региональная экономика. Юг России. 2019. - T. 7, № 1. - C. 18-28. - DOI: https:// doi.org/10.15688/re.volsu.2019.1.2.

Воронов, В. В. Конвергенция регионов Европейского союза: особенности и оценка / В. В. Воронов // Экономические и социальные перемены: факты, тенденции, прогноз. - 2014. - № 6. - С. 8599. -DOI: https://doi.org/10.15838/esc.2014.6.36.7.

Иванов, О. Б. «Перспективная экономическая специализация» как новация политики регионального развития / О. Б. Иванов, Е. М. Бухвальд // ЭТАП: экономическая теория, анализ, практика. - 2019. - № 6. - С. 49-65.

Котов, А. В. Экспортоориентированная сырьевая модель российской экономики: в поисках новой модели пространственного развития / А. В. Котов // Национальная безопасность и стратегическое планирование. - 2019. № 2. - С. 5-16.

Лексин, В. Н. Дороги, которые мы не выбираем (о правительственной «Стратегии пространственного развития Российской Федерации на период до 2025 года») / В. Н. Лексин // Российский экономический журнал. - 2019. - № 3. - С. 3-24.
Минакир, П. А. Российское экономическое пространство: стратегические тупики / П. А. Минакир //Экономика региона. - 2019. - Т. 15, № 4. -С. 967980.-DOI: https://doi.org/10.17059/2019-4-1.

Митрофанова, И. В. Макрорегион как утверждающаяся форма территориальной институции / И. В. Митрофанова // Национальные интересы: приоритеты и безопасность. 2008. - Т. 4, № 8. - С. 30-40.

Наумов, И. В. Исследование межрегиональных взаимосвязей в процессе развития минеральносырьевого комплекса Российской Федерации / И. В. Наумов, С. С. Красных // Известия высших учебных заведений. Горный журнал. 2019. - № 8. - С. 108-124.

Преображенский, Ю. В. Районирование Урало-Поволжья для целей пространственного планирования / Ю. В. Преображенский // Известия Саратовского университета. Новая серия. Серия: Науки о Земле. - 2019. - Т. 19, вып. 2. C. 97-103. - DOI: https://doi.org/10.18500/18197663-2019-19-2-97-103.

Распоряжение Правительства РФ от 13.02.2019 № 207-р «Об утверждении Стратегии пространственного развития до 2025 года» // Правительство Российской Федерации. - Электрон. текстовые дан. - Режим доступа: http:// static.government.ru/media/files/UVAlqUtT08 o60RktoOX122JjAe7irNxc.pdf(дата обращения: 10.05.2020). - Загл. с экрана.

Рой, О. М. Эволюция и перспективы макрорегионального регулирования в России / О. М. Рой // Вестник Омского университета. Серия: Экономика. - 2012. - № 1. - С. 5-11.

Чертков, А. Н. Макрорегионы в территориальном устройстве Российской империи / А. Н. Чертков // История государства и права. - 2011. № 20. - C. 29-33.

Barrios, C. Club Convergence in Innovation Activity Across European Regions / C. Barrios, E. Flores, M. M. Angeles // Papers in Regional Science. 2019. - Vol. 98, №4. - P. 1545-1565. - DOI: https:// doi.org/10.1111/pirs.12429.

Barro, R. J. Economic Growth in a Cross Section of Countries / R. J. Barro // The Quarterly Journal of Economics. - 1991. - Vol. 106, № 2. - P. 407-443.

Barro, R. J. Convergence / R. J. Barro, X. Sala-i-Martin // Journal of Political Economy. - 1992. - Vol. 100, № 2. - P. 223-251.

Bartkowska, M. Regional Convergence Clubs in Europe: Identification and Conditioning Factors / M. Bartkowska, A. Riedl // Economic Modelling. - 2012. - Vol. 29. - P. 22-31.-DOI: https://doi.org/10.1016/j.econmod.2011.01.013.

Borsekova, K. Smart Specialization for Smart Spatial Development: Innovation Strategies for Building 
Competitive Advantages in Tourism in Slovakia / K. Borsekova, A. Vanova, K. Vitalisova // SocioEconomic Planning Sciences. - 2017. - Vol. 58, № 10. - P. 39-50. - DOI: https://doi.org/10.1016/ j.seps.2016.10.004.

Brenner, T. Specialization and Convergence of IndustrySpecific Employment in Germany: A Linear MixedModel Approach with Spatial Components / T. Brenner, G. Kauermann // Regional Studies. 2016. - Vol. 50, № 2. - P. 326-341. -DOI: https:// doi.org/10.1080/00343404.2014.920082.

Capello, R. Competitiveness Through Integration in the European Union Strategy for the Alpine Region: A "Balanced Development" Approach / R. Capello, S. Cerisola // European Planning Studies. - 2019. - Vol. 27, № 5. - P. 1013-1034. DOI:https://doi.org/10.1080/09654313.2019.1588860.

Chapman, S. Behind the Pan-European Convergence Path: The Role of Innovation, Specialisation and Socio-Economic Factors / S. Chapman, V. Meliciani // Growth and Change. - 2017. Vol. 48, № 1. - P. 61-90. - DOI: https://doi.org/ 10.1111/grow. 12148 .

Duque, J. C. Supervised Regionalization Methods: A Survey/ J. C. Duque, R. Ramos, J. Surinach // International Regional Science Review. 2007. - Vol. 30, № 3. - P. 195-220. - DOI: https:// doi.org/10.1177/0160017607301605.

Foray, D. Smart Specialization Strategies and Industrial Modernization in European Regions - Theory and Practice / D. Foray // Cambridge Journal of Economics. - 2018. - Vol. 42, № 6. - P. 15051520. - DOI: https://doi.org/10.1093/cje/bey022.

Galor, O. Convergence? Inferences from Theoretical Models / O. Galor // The Economic Journal. 1996. - Vol. 106, № 437. - P. 1056-1069. - DOI: https://doi.org/10.2307/2235378.

Islam, N. What Have We Learnt from the Convergence Debate? / N. Islam // Journal of Economic Surveys. - 2003. - Vol. 17, № 3. - P. 309-362. DOI: https://doi.org/10.1111/1467-6419.00197.

Karlsson, C. The Identification of Functional Regions: Theory, Methods, and Applications / C. Karlsson, M. Olsson // Annals of Regional Science. 2006. - Vol. 40, № 1. - P. 1-18. - DOI: https:// doi.org/10.1007/s00168-005-0019-5.

Kinfemichael, B. Convergence of Labor Productivity Across the US States / B. Kinfemichael, A. K. M. M. Morshed// Economic Modelling. 2019. - Vol. 76. - P. 270-280. - DOI: https:// doi.org/10.1016/j.econmod.2018.08.008.

Marelli, E. P. Economic Convergence in the EU and Eurozone/ E. P. Marelli, M. L. Parisi, M. Signorelli // Journal of Economic Studies. - 2019. - Vol. 46, № 7.-P. 1332-1344.-DOI:https://doi.org/10.1108/ jes-03-2019-0139.
Monfort, M. Inequality and Unemployment Patterns in Europe: Does Integration Lead to (Real) Convergence? / M. Monfort, J. Ordonez, H. Sala // Open Economies Review. - 2018. - Vol. 29, № 4. - P. 703-724. - DOI: https://doi.org/10.1007/ s11079-018-9488-X.

Napolitano, O. Stochastic Convergence or Divergence of Total Factor Productivity and GDP of Italian Regions. Re-Examing the Evidence/O. Napolitano, M. Pietroluongo, K. Kounetas // Economics Bulletin. -2018. - Vol. 38, № 4.-P. 1857-1863.

Ranga, M. Smart Specialization as a Strategy to Develop Early-Stage Regional Innovation Systems / M. Ranga // European Planning Studies. -2018. Vol. 26, № 11.-P.2125-2145. -DOI: https://doi.org/ 10.1080/09654313.2018.1530149.

Sala-i-Martin, X. Regional Cohesion: Evidence and Theories of Regional Growth and Convergence / X. Sala-i-Martin // European Economic Review. 1996. - Vol. 40, №6. -P. 1325-1352. - DOI: https:// doi.org/10.1016/0014-2921(95)00029-1.

Smart Specialization Policy in the European Union: Relatedness, Knowledge Complexity and Regional Diversification / P.-A. Balland [et al.] // Regional Studies. - 2019. - Vol. 53, № 9. - P. 1252-1268. DOI: https://doi.org/10.1080/00343404.2018.1437900.

\section{REFERENCES}

Blanutsa V.I. Sotsialno-ekonomicheskoe rayonirovanie $v$ epokhu bolshikh dannykh [Socio-Economic Regionalization in the Era of Big Data]. Moscow, INFRA-M Publ., 2018a. 194 p.

Blanutsa V.I. Territorialnaya struktura tsifrovoy ekonomiki Rossii: predvaritelnaya delimitatsiya «umnykh» gorodskikh aglomeratsiy i regionov [Territorial Structure of the Digital Economy of Russia: Preliminary Delimitation of "Smart" Urban Agglomerations and Regions]. Prostranstvennaya Ekonomika, 2018b, no. 2, pp. 17-35. DOI: https://doi.org/10.14530/se.2018. 2.017-035.

Blanutsa V.I. Tsifrovaya ekonomika Sibiri: territorialnye platformy dlya klasterov [Digital Economy of Siberia: Territorial Platforms for Clusters]. Aktualnye Problemy Ekonomiki i Prava, 2019, vol. 13, no. 3, pp. 1362-1374. DOI: https://doi.org/ 10.21202/1993-047X.13.13.2019.3.

Bukhwald E.M., Valentik O.N. Makroregiony kak novatsiya strategirovaniya prostranstvennogo razvitiya ekonomiki Rossii [Macro-Regions as an Innovation in the Spatial Development of the Russian Economy]. Regionalnaya Ekonomika. Yug Rossii, 2019, vol. 7, no. 1, pp. 18-28. DOI: https://doi.org/10.15688/re.volsu.2019.1.2. 
Voronov V. V. Konvergentsiya regionov Evropeyskogo soyuza: osobennosti i otsenka [Convergence of Regions of the European Union: Features and Assessment]. Ekonomicheskie $i$ Sotsialnye Peremeny: fakty, tendentsii, prognoz, 2014, no. 6, pp. 85-99. DOI: https://doi.org/10.15838/ esc.2014.6.36.7.

Ivanov O.B., Bukhvald E.M. «Perspektivnaya ekonomicheskaya spetsializatsiya» kak novatsiya politiki regionalnogo razvitiya ["Perspective Economic Specialization" as an Innovation in Regional Development Policy]. ETAP: ekonomicheskaya teoriya, analiz, praktika, 2019, no. 6, pp. 49-65.

Kotov A.V. Eksportoorientirovannaya syrevaya model rossiyskoy ekonomiki: v poiskakh novoy modeli prostranstvennogo razvitiya [Export-Oriented Raw Material Model of the Russian Economy: In Search of a New Model of Spatial Development]. Natsionalnaya bezopasnost i strategicheskoe planirovanie, 2019, no. 2, pp. 5-16.

Leksin V.N. Dorogi, kotorye my ne vybiraem (o pravitelstvennoy «Strategii prostranstvennogo razvitiya Rossiyskoy Federatsii na period do 2025 goda») [Roads That We Do not Choose(On the Governments "Strategy for the Spatial Development of the Russian Federation for the Period Until 2025")]. Rossiyskiy ekonomicheskiy zhurnal, 2019, no. 3, pp. 3-24.

Minakir P.A. Rossiyskoe ekonomicheskoe prostranstvo: strategicheskie tupiki [Russian Economic Space: Strategic Dead Ends]. Ekonomika regiona, 2019, vol. 15, no. 4, pp. 967-980. DOI: https://doi.org/ 10.17059/2019-4-1.

Mitrofanova I.V. Makroregion kak utverzhdayushchayasya forma territorialnoy institutsii [Macro-Region as an Affirmed Form of Territorial Institution]. Natsionalnye interesy: prioritety i bezopasnost, 2008, vol. 4, no. 8, pp. 30-40.

Naumov I.V., Krasnykh S.S. Issledovanie mezhregionalnykh vzaimosvyazey v protsesse razvitiya mineralno-syryevogo kompleksa Rossiyskoy Federatsii [Study of Interregional Relationships in the Development of the Mineral Resource Complex of the Russian Federation]. Izvestiya vysshikh uchebnykh zavedeniy. Gornyy zhurnal, 2019, no. 8, pp. 108-124.

Preobrazhensky Yu.V. Rayonirovanie Uralo-Povolzhya dlya tseley prostranstvennogo planirovaniya [Zoning of the Ural-Volga Region for Spatial Planning]. Izvestiya Saratovskogo universiteta. Novaya seriya. Seriya Nauki o Zemle, 2019, vol. 19, iss. 2, pp. 97-103. DOI: https://doi.org/ 10.18500/1819-7663-2019-19-2-97-103.

Rasporyazhenie Pravitelstva RF ot 13.02.2019 № 207-r «Ob utverzhdenii Strategii prostranstvennogo razvitiya do 2025 goda» [Decree of the Government of the Russian Federation of February 13, 2019 No. 207-r "On Approval of the Strategy for Spatial Development Until 2025"]. Pravitelstvo Rossiyskoy Federatsii [Government of the Russian Federation]. URL: http://static. government.ru/media/files/ UVAlqUtT08060 RktoOX122JjAe7irNxc.pdf (accessed 10 May 2020).

Roy O.M. Evolyutsiya i perspektivy makroregionalnogo regulirovaniya v Rossii [Evolution and Prospects of Macro-Regional Regulation in Russia]. Vestnik Omskogo universiteta. Seriya: Ekonomika, 2012, no. 1 , pp. 5-11.

Chertkov A.N. Makroregiony v territorialnom ustroystve Rossiyskoy imperii [Macro-Regions in the Territorial Structure of the Russian Empire]. Istoriya gosudarstva i prava, 2011, no. 20, pp. 29-33.

Barrios C., Flores E., Angeles M.M. Club Convergence in Innovation Activity Across European Regions. Papers in Regional Science, 2019, vol. 98, no. 4, pp. 1545-1565. DOI: https://doi.org/10.1111/ pirs. 12429.

Barro R.J. Economic Growth in a Cross Section of Countries. The Quarterly Journal of Economics, 1991, vol. 106, no. 2, pp. 407-443.

Barro R.J., Sala-i-Martin X. Convergence. Journal of Political Economy, 1992, vol. 100, no. 2, pp. 223-251.

Bartkowska M., Riedl A. Regional Convergence Clubs in Europe: Identification and Conditioning Factors. Economic Modelling, 2012, vol. 29, pp. 22-31. DOI: https://doi.org/10.1016/j. econmod.2011.01.013.

Borsekova K., Vanova A., Vitalisova K. Smart Specialization for Smart Spatial Development: Innovation Strategies for Building Competitive Advantages in Tourism in Slovakia. SocioEconomic Planning Sciences, 2017, vol. 58, no. 10, pp. 39-50. DOI: https://doi.org/10.1016/ j.seps.2016.10.004.

Brenner T., Kauermann G. Specialization and Convergence of Industry-Specific Employment in Germany: A Linear Mixed-Model Approach with Spatial Components. Regional Studies, 2016, vol. 50, no. 2, pp. 326-341. DOI: https:// doi.org/10.1080/00343404.2014.920082.

Capello R., Cerisola S. Competitiveness Through Integration in the European Union Strategy for the Alpine Region: A "Balanced Development" Approach. European Planning Studies, 2019, vol. 27, no. 5, pp. 1013-1034. DOI: https://doi.org/ 10.1080/09654313.2019.1588860.

Chapman S., Meliciani V. Behind the Pan-European Convergence Path: The Role of Innovation, 
Specialisation and Socio-Economic Factors. Growth and Change, 2017, vol. 48, no. 1, pp. 6190. DOI: https://doi.org/10.1111/grow. 12148 .

Duque J. C., Ramos R., Surinach J. Supervised Regionalization Methods: A Survey. International Regional Science Review, 2007, vol. 30, no. 3, pp. 195-220. DOI: https://doi.org/ $10.1177 / 0160017607301605$.

Foray D. Smart Specialization Strategies and Industrial Modernization in European Regions - Theory and Practice. Cambridge Journal of Economics, 2018, vol. 42, no. 6, pp. 1505-1520. DOI: https:// doi.org/10.1093/cje/bey022.

Galor O. Convergence? Inferences from Theoretical Models. The Economic Journal, 1996, vol. 106, no. 437 , pp. $1056-1069$. DOI: $10.2307 / 2235378$.

Islam N. What Have We Learnt from the Convergence Debate? Journal of Economic Surveys, 2003, vol. 17, no. 3, pp. 309-362. DOI: https://doi.org/ 10.1111/1467-6419.00197.

Karlsson C., Olsson M. The Identification of Functional Regions: Theory, Methods, and Applications. Annals of Regional Science, 2006, vol. 40, no. 1, pp. 1-18. DOI: https://doi.org/10. 1007/s00168-005-0019-5.

Kinfemichael B., Morshed A.K.M.M. Convergence of Labor Productivity Across the US States. Economic Modelling, 2019, vol. 76, pp. 270-280. DOI: https:// doi.org/10.1016/j.econmod.2018.08.008.
Marelli E.P., Parisi M.L., Signorelli M. Economic Convergence in the EU and Eurozone. Journal of Economic Studies, 2019, vol. 46, no. 7, pp. 13321344. DOI: https://doi.org/10.1108/jes-03-2019-0139.

Monfort M., Ordonez J., Sala H. Inequality and Unemployment Patterns in Europe: Does Integration Lead to (Real) Convergence? Open Economies Review, 2018, vol. 29, no. 4,pp. 703-724.DOI: https:/ /doi.org/10.1007/s11079-018-9488-x.

Napolitano O., Pietroluongo M., Kounetas K. Stochastic Convergence or Divergence of Total Factor Productivity and GDP of Italian Regions. Re-Examing the Evidence. Economics Bulletin, 2018, vol. 38, no. 4, pp. 1857-1863.

Ranga M. Smart Specialization as a Strategy to Develop Early-Stage Regional Innovation Systems. European Planning Studies, 2018, vol. 26, no. 11, pp. 2125-2145. DOI: https:// doi.org/10.1080/09654313.2018.1530149.

Sala-i-Martin X. Regional Cohesion: Evidence and Theories of Regional Growth and Convergence. European Economic Review, 1996, vol. 40, no. 6, pp. 1325-1352. DOI: https://doi.org/10. 1016/0014-2921(95) 00029-1.

Balland P.-A. et al. Smart Specialization Policy in the European Union: Relatedness, Knowledge Complexity and Regional Diversification. Regional Studies, 2019, vol. 53, no. 9, pp. 1252-1268. DOI: https://doi.org/10.1080/00343404.2018.1437900.

\section{Information About the Author}

Viktor I. Blanutsa, Doctor of Sciences (Geography), Leading Researcher, V.B. Sochava Institute of Geography of Siberian Branch of the Russian Academy of Sciences, Ulan-Batorskaya St, 1, 664033 Irkutsk, Russian Federation, blanutsa@list.ru, https://orcid.org/0000-0003-3958-216X

\section{Информация об авторе}

Виктор Иванович Блануца, доктор географических наук, ведущий научный сотрудник, Институт географии им. В.Б. Сочавы СО РАН, ул. Улан-Баторская, 1, 664033 г. Иркутск, Российская Федерация, blanutsa@list.ru, https://orcid.org/0000-0003-3958-216X 